\title{
Study on the Mechanism of Science and Technology in Poverty Alleviation
}

\author{
—-A Case Study of Science and Technology Poverty Alleviation in Sichuan \\ Manlu Yang ${ }^{1, a}$, Yu $\mathrm{He}^{1, b}$ \\ ${ }^{1}$ Sichuan Agricultural University, Chengdu, Sichuan, 61130
}

\begin{abstract}
Keywords: Science and Technology Poverty Alleviation, Comprehensive Well-off, Precision Poverty Alleviation, Sichuan Model
\end{abstract}

\begin{abstract}
The 18th National Congress of the Communist Party of China put forward the concept of shared development. It is clear that all the poor areas and poor people in the country will enter a comprehensive well-off society in 2020. Sichuan Province will play a supporting role in poverty alleviation and promote poverty by using innovation. This paper analyzes the current situation of science and technology poverty alleviation in Sichuan, the main mode and effect of science and technology poverty alleviation, and puts forward some problems such as lack of incentive science and technology personnel in science and technology poverty alleviation, low degree of marketization of agricultural science and technology service industry, lack of talent resources and financing difficulties of small and medium- From the encouragement of scientific and technological personnel to help the poor, cultivate the main agricultural science and technology services, innovation and technology services and poverty alleviation mechanism of poverty alleviation mechanism put forward countermeasures and suggestions.
\end{abstract}

\section{Introduction}

Since the 18th National Congress of the Communist Party of China (CPC), the party and the government have put the work of poverty alleviation into a more prominent position, vigorously, wide-ranging, multi-level and forward, and made great efforts to fill the short- The implementation of precision poverty alleviation, and create a new situation of poverty alleviation and development. According to the minimum poverty alleviation standard of 2855 yuan per capita net income of farmers, the rural poverty population has decreased from 160 million in 2010 to about 60 million by the end of 2015, a total reduction of 100 million people, increasing financial investment in poverty-stricken areas, and significantly improved infrastructure , Industry poverty alleviation in the ascendant, social security is increasingly perfect, for the full build a moderately prosperous society laid a solid foundation.

Science and technology poverty alleviation is an important part of the state's implementation of precision poverty alleviation and poverty alleviation strategy. The core of the essence, is to give full play to scientific and technological innovation in precision poverty alleviation and poverty alleviation in the leading role in the promotion of science and technology through the popularization of science and technology and the use of science and technology to promote the improvement of technology, talent and other innovative elements of the supply of workers to enhance the scientific and technological culture Quality and survival and development capacity, and improve the scientific quality of poor households and production skills. Especially in the development of poverty-stricken areas, the advantages of industry, through the development of entrepreneurial poverty alleviation, to enhance the vocational skills of poor households to enhance the endogenous development of poverty-stricken areas, science and technology, intelligence and industry to support poverty-stricken areas and the poor to accelerate the pace of poverty, Well - off society.

\section{Sichuan Science and Technology Poverty Alleviation Status}

To eliminate absolute poverty as the goal, to precision poverty alleviation precision as a means to 
give full play to science and technology in poverty alleviation in the support role, the use of innovation to achieve poverty alleviation and development.

Sichuan's poor rural areas have three main characteristics: one is wide, large, deep. In 2015, the province's rural poor population of 380.29 million people, the incidence of poor people reached $5.88 \%$, the poverty population accounted for $7.1 \%$ of the population; poor villages 11501 , accounting for $9 \%$ of the country, poor areas involving 20 cities State, 160, the number of poor villages 11501, accounting for 9\% of the country, of which the national contiguous development of four (Qinba mountain, Wumeng mountain, the size of Liangshan Yi, plateau Tibetan), the national key poverty counties 88 The Second, the causes of poverty and poverty reduction superposition, major diseases, major disasters, the lack of funds is an important reason. Third, poor development constraints in poor areas, low level of industry, poverty alleviation is difficult.

Since November 2015, Sichuan has made protection and improvement of people's livelihood as the starting point and the foothold of all the work, focusing on the "four areas" precision poverty alleviation, made a "poverty alleviation" of the overall design and institutional arrangements, by 2020, the province More than 380 million poor people all out of poverty, simultaneously to achieve a comprehensive well-off, while the annual development of poverty alleviation goals, and developed a series of major policy initiatives, including science and technology poverty alleviation, industry poverty alleviation and other 17 special programs, Batch "work initiatives," six precision "work requirements. In 2016, the actual poverty alleviation was 107.8 million, the rural poverty population decreased to 272.29 million, the incidence of poverty dropped to $4.4 \%$, overrun rate was $102.7 \%$.

From the above two sites data compiled data (see Table 1), "Twelve Five" since the number of poor people in Sichuan Province decreased year by year, Sichuan according to its actual situation, problem-oriented, in the poverty alleviation in the precision force, clear objectives , Measures properly, poverty alleviation effect is remarkable.

Table 1 The number of poor people in Sichuan and the incidence of poverty

\begin{tabular}{lcc}
\hline Year & Number of poor people (million) & The incidence of poverty (\%) \\
\hline 2011 & 1356 & 16.8 \\
2012 & 750 & 11.5 \\
2013 & 602 & 8.6 \\
2014 & 497.65 & 7.7 \\
2015 & 380.29 & 5.88 \\
2016 & 272.49 & 4.4 \\
\hline
\end{tabular}

Sichuan science and technology to help focus on improving the ability of science and technology support in poverty-stricken areas, to build a long-term mechanism of science and technology poverty alleviation, and enhance the "hematopoietic" function of poverty-stricken areas, to promote industrial development with technological progress, to enhance the scientific and cultural quality of farmers to enhance their own development capacity, Driven, industry-driven, entrepreneurial pull, school (hospital) to linkage, online interaction of science and technology poverty alleviation model.

In order to establish a new science and technology service organization focusing on the online service platform of science and technology poverty alleviation, this paper has adopted the "Internet + Technology" as the means to integrate the major channels of communication technology, such as the lack of communication channels, the shortage of experts and the scatter of science and technology resources. Government, universities, institutions, leading enterprises, business and other scientific and technological resources and social resources, the establishment of the "Sichuan Science and Technology Poverty Alleviation Online" platform, tens of thousands of experts and tens of thousands of information officers, the establishment of the provincial, Management center, to achieve the nearest, in situ to help those who do not have the ability and conditions of poor online demand for technical needs and provide online technical services for all types of business entities to provide technical support; integrated release covers varieties, technology, processing, storage and transportation industry Chain of agricultural technology results information, macro industry and local characteristics of industry information, leading enterprises and other information. As of 
November 20, 2016, online platform visits amounted to 93.1 million times, dispatch the province's scientific and technological resources to carry out information services 4046 times to complete the answer 3680 times.

Strengthen the industry to support poverty alleviation technology support, cultivate and expand the characteristics of poor areas of industry, the depth of the development of four contiguous development zones of grain and oil, fruits and vegetables, tea, silkworm mulberry, livestock, dairy, bamboo, Chinese herbal medicine and other characteristics of resources, Industrial chain extension as a breakthrough, to determine the 2020, foster 10-30 billion innovative industrial enterprises leading more than 30, the development and expansion of 500-1000 billion yuan of modern agricultural industry 5-8, to achieve sustainable development of poverty alleviation. Since the beginning of 2016 in Sichuan for the implementation of industrial development in poverty-stricken areas, science and technology service platform construction, scientific and technological personnel service incentives and other aspects of science and technology plans to increase poverty funds increased by 1.4 times over the previous year to support the number of stable and high-yield projects (see Table 2), To enhance the poverty-stricken areas of industry science and technology gold content, promote industrial development, enhance regional economic strength.

Table 2 Sichuan science and technology poverty alleviation plan to support the amount of funds and support the number of projects

\begin{tabular}{ccc}
\hline Year & Amount of money (ten thousand yuan) & Number of items \\
\hline 2011 & 3500 & 182 \\
2012 & 3500 & 186 \\
2013 & 4000 & 196 \\
2014 & 4000 & 201 \\
2015 & 5000 & 205 \\
2016 & 12000 & 212 \\
\hline
\end{tabular}

In order to solve the problems of poverty-stricken areas, lack of funds, lack of industry, lack of talent and other issues, the organization of scientific and technological personnel with technology, projects, funds and other poverty-stricken areas to carry out scientific and technological assistance, the industrial chain, value chain and other modern industrial organizations into agriculture, Open up the last mile of research and market. The

The construction of science and technology poverty alleviation service system, the establishment of four major areas of science and technology poverty alleviation group, mobilize 30 colleges and universities, institutions to establish a mechanism for poverty alleviation, the construction of incubation park, business park, entrepreneurial nursery and other stars create heaven and earth, for agricultural science and technology personnel to provide entrepreneurship Platform support.

Encourage scientific and technological personnel in poverty-stricken areas to set up leading agricultural science and technology park agricultural science and technology expert compound, professional cooperation organization, rural industrial technology service center and other science and technology poverty alleviation service agencies, founder of leading enterprises, the development of industry.

To carry out technical services for the local enterprises, communes, family farms and other new agricultural operators to provide technical advice, technical consultants, product development, practical promotion and other technical services to solve the problem of industrial science and technology in poverty-stricken areas.

It has established a commercial breeding, public welfare breeding research, innovation platform (base) and other projects according to its different industrial categories, such as agriculture, forestry, animal, aquatic and other breakthrough varieties. Innovative breeding theory and methods, create excellent breeding materials and breeding fine varieties, and vigorously promote agricultural and livestock breeding research, consolidate the industrial development of improved seed support. 


\section{Analysis of the Problems in the Poverty Alleviation by Science and Technology}

At present, both the fruit industry, the nursery stock industry, or the aquaculture industry, the scientific and technological content is very high, the scientific and technological literacy requirements of the farmers are also high, and the science and technology poverty alleviation is mainly supported by the knowledge and skills of the backward farmers, these farmers are common Low quality, lack of ideas, scientific and technological awareness is not strong, production skills, the ability is relatively poor and other issues, science and technology and technology conversion applications at the same time by the degree of awareness constraints, which led to the greater risk of service activities, Achievements to promote the use of slow. Scientific and technological personnel technical services, technical advice, technical training and other scientific and technological achievements into the activities of the intellectual labor and time costs are correspondingly increased, affecting the enthusiasm of scientific and technological personnel to help the poor mainly in:

The actual contribution of scientific and technological personnel and income distribution does not match, by the institutions of the wage distribution system constraints, in particular, the total unit performance of the total wage limit, the unit incentive science and technology personnel poverty alleviation measures.

The leadership positions of scientific and technological personnel to enjoy the innovation and entrepreneurship incentive policy problems. Institutions of higher learning, scientific research institutes, agricultural extension and other units, a considerable part of the leadership positions of scientific and technological personnel are technical backbone, with a large number of outstanding achievements, due to the prohibition of leading cadres to do business and part-time salary limit, Scientific and technological personnel innovation and entrepreneurship incentive policy implementation of the existence of fuzzy boundaries, there are concerns.

In the evaluation of talent still exist re-education, light ability, heavy qualifications, light performance, heavy paper, light contribution, heavy recent, light long-term, re-show, light potential, heavy quantity, light quality " "The phenomenon. In addition, science and technology poverty alleviation work by the poor areas of the economy is relatively backward and lack of funds and other conditions, affecting the scientific and technological personnel development and transformation of the results.

The rapid development of science and technology economy The operation mode of agricultural science and technology service organization will gradually become more and more market-oriented to the requirements of agricultural science and technology service, so that science and technology service agencies must speed up the management concept of innovation and improve the effectiveness of science and technology services. Sichuan Province engaged in agricultural science and technology activities in the organization, the proportion of institutions up to 63\%, business units accounted for only $11 \%$ of the total number of institutions. As with most parts of the country, the agricultural science and technology service industry in Sichuan Province is mainly dominated by government, and the process of marketization is slow. Although the weak nature of agriculture and public welfare, making the agricultural science and technology service industry to a certain extent, can not be separated from the government's support and guidance, but too lack of market-oriented operation mechanism, will lead to competition awareness, ideas, And then lead to the results of slow conversion, intellectual property protection difficulties, the lack of technical market standards and a series of problems, thus affecting the entire industry's long-term development.

Agricultural science and technology service industry is a typical knowledge-based service industry, mainly through the employment of intellectual workers to provide services and access to income, with a clear knowledge, intelligence-intensive features. Service organization and its professional characteristics, determines its knowledge content to provide services, high technical content, practitioners of scientific research capabilities, knowledge structure and technical level to meet the requirements. Sichuan Province, agricultural science and technology service industry science and technology activities accounted for only 3\% of the province's total technology services, 
human resources is weak. Modern science and technology service industry on the quality of employees put forward a higher demand: practitioners not only need to have a high professional knowledge, but also need to have management, management and other complex knowledge. Sichuan Province, modern agricultural science and technology services required for the shortage of high-quality professionals affected the industry to improve service awareness, limiting the overall service capacity of the industry to enhance.

Agricultural science and technology service is a whole process, one-stop, all-round systematic service, not only from the technology research and development, application of scientific and technological achievements, industrialization and other processes, including agriculture and technology enterprises, including incubation, market development, Innovation training, personnel exchanges and other systematic, social services. Diversified market demand requires that agricultural science and technology services must establish demand-oriented mechanisms and continue to move towards diversified and diversified services. At present, Sichuan agricultural science and technology service industry in the production and research cooperation, science and technology investment and financing services in short supply. The type of science and technology services in Sichuan is relatively concentrated and single, heavy single service and light integrated services, pre-production services and light and post-harvest, especially management, management services, resulting in supply and demand between the structural contradictions are more prominent To meet the new stage of development needs.

Sichuan Province has initially formed a bank, venture capital, venture capital to complement each other's technology financial services system, but the financial capital in the entire capital investment system accounted for a small proportion. Such as 2006 to 2014, Sichuan Province, agricultural science and technology achievements in the total project funding, bank loans accounted for only about $1.5 \%$, and can get loans are mostly large enterprises. It is difficult to obtain loans from the banking system because of the property rights, finance, management and other reasons, coupled with the uncertainty of agricultural production, financing is difficult to become troubled Sichuan agricultural science and technology development of small and medium-sized enterprises long-term problems.

At present in the technical support, the main existence of professional service level to be improved, the construction of public technical support platform lag and other issues. In the market economy, there is mainly lack of investment in science and technology activities, industry development to be standardized and other issues. In the policy environment, there are mainly supporting policy is not perfect problem. In the social environment, there are mainly problems in the operation of the institutional mechanism, which also more or less affect the agricultural science and technology service activities carried out, restricting the overall development of agricultural services.

\section{Promote Science and Technology in Sichuan Poverty Alleviation Countermeasures and Suggestions}

The more difficult, the more difficult, more compelling the responsibility, precise policy, too fine work, enhance the "hematopoietic" function of science and technology poverty alleviation to problem-oriented, precision force, innovation and technology help precision out of poverty ideas and ways to deal with Good external support and internal forces, play a scientific and technological "multiplier" role, gather effective resources, take effective measures to make science and technology poverty alleviation to achieve greater effectiveness.

Whether the success of science and technology poverty alleviation depends on the common role of market mechanism, the farmers' needs and scientific and technological has personnel knowledge. While strengthening the function of "hematopoietic" in poverty-stricken areas, the scientific and technological departments should establish a sound science and technology poverty alleviation and stabilize the poverty Mechanism, so that scientific and technological knowledge really penetrate into the agricultural industry, accelerate the transformation of scientific research into the pace of real productive forces, improve the scientific and technological content of agricultural products, 
cultivate more love agriculture, understand the technology, good management of new professional farmers, so that the majority of farmers really Rely on science and technology to get rid of poverty.

To carry out science and technology poverty alleviation with professional and technical personnel is to enhance farmers' scientific and technological literacy. At present, whether it is fruit forestry, nursery stock industry, or aquaculture, scientific and technological content is very high, the technical requirements of farmers is also high. Farmers in the production process need to improve their own science and technology. Many districts and counties have integrated the city (district) county science and technology, the formation of science and technology poverty alleviation team, to fixed, tour, technical contract and other forms, for low-income villages to provide convenient and effective technology services. Some places are exploring to encourage scientific and technological personnel to technology shares and other forms of co-founder of professional cooperatives or agricultural enterprises.

Talent is the first resource, human capital is the most important capital, reflecting the increase in knowledge value of the income distribution mechanism and improve the talent evaluation mechanism, so that scientific and technological personnel income and poverty alleviation performance, the actual contribution closely linked to stimulate scientific and technological personnel to promote poverty and innovation and entrepreneurship vitality. Sichuan should be used to be included in the national comprehensive innovation reform pilot area of the opportunity for poverty alleviation of scientific and technological personnel in the performance incentive talent evaluation and a bold breakthrough, first try.

To expand the performance of the distribution of wages, improve the allocation of incentives, the unit to determine the performance appraisal methods and performance pay distribution, performance pay for poverty alleviation of scientific and technological personnel, key positions, high-level personnel, business backbone and other personnel tilt, The performance of the staff due to poverty alleviation of the performance of a single pay, not limited by the total performance of the unit pay.

To encourage enterprises, institutions of higher learning, research institutes and other enterprises and institutions, in poverty-stricken areas to carry out scientific and technological achievements and technological development, technical services, technical advice and other activities to obtain the proceeds, improve the scientific and technical personnel reward and compensation

To allow the appointment of institutions of higher learning, scientific research institutes and other units above the leadership of scientific and technical personnel to the poor areas part-time engaged in scientific and technological achievements into activities, and obtain the corresponding income.

Institutions of higher learning, scientific research institutes and other units under the leadership of scientific and technological personnel, is the main completion of scientific and technological achievements or scientific and technological achievements in poverty-stricken areas to make an important contribution to the conversion, allowing them to obtain equity awards.

To allow scientific and technological personnel to technology and capital participation in poor areas of professional cooperatives, industry and leading enterprises, the two sides form a community of economic interests, the implementation of risk sharing, benefit sharing, the formation of close integration, collaboration and mutual support of the new relationship, so that scientific and technological personnel In the transformation of scientific and technological achievements at the same time, but also the innovation and entrepreneurial activities closely together, both to reduce the production and operation of entities to introduce technology costs, but also reduce the use of new technology, the objective risk and subjective risks, but also to make scientific and technical personnel reasonable Return.

Improve the role of talent evaluation baton, for scientific and technological personnel in poverty alleviation work to play the role of talent, to display their talent to solve worries. Should improve the evaluation of science and technology talent classification model, improve the innovation and transformation of the talent evaluation system, in the title assessment and post employment for poverty alleviation of scientific and technological personnel tilt; in the job evaluation and post 
employment, scientific and technical personnel in poverty-stricken areas to carry out technical services (technology development, Technical advice, the results of the conversion) and other activities to obtain funding, presided over the development of scientific and technological achievements transfer of turnover as the vertical project funding, scientific and technological achievements into the application requirements and the same requirements. In the poverty-stricken areas part-time scientific and technical personnel do not treat the paper as the evaluation of the restrictive conditions, professional foreign language and computer application capacity is not a unified requirement, part-time creation of scientific and technological achievements as the title assessment and the original unit positions an important basis for employment.

As scientific and technical personnel are the backbone of the technical, with a large number of outstanding achievements, and have more human resources, allowing institutions of the other members of the leadership team and their respective faculties and institutions of higher education, scientific research institutes, agricultural extension and other institutions of leadership positions are scientific and technical personnel , The scientific and technical personnel who hold the position of the organization, go to the professional cooperatives in the poverty-stricken areas, industrial large enterprises and enterprises to engage in part-time activities, and refer to the "National Promotion of Science and Technology Achievements" reward rules, that is conducive to the results of transformation, and The use of poverty in the region cited only Zhizhi.

At this stage, diversified market demand requires that agricultural science and technology services must establish demand-oriented mechanisms and continue to move towards diversified and diversified services. Improve the agricultural science and technology service system, establish a wide-ranging, multi-level agricultural science and technology service industry system, in depth to promote the "provinces, regions, cities, counties (districts)" four agricultural science and technology service system; Science and technology park, agricultural science and technology experts compound, science and technology correspondent and institutions of higher learning and other professional service agencies, science and technology enterprises to carry out business cooperation, the formation of "prenatal, middle and postpartum" whole industry chain agricultural science and technology service system; Poverty-stricken areas advantages, leading enterprises and institutions of higher learning, scientific research institutes to build key laboratories, engineering and technology research centers, industrial technology research institutes and industrial technology innovation strategic alliance and other innovation platform. Third, nurturing and gathering a number of social investment, professional services, agricultural service agencies, the formation of a linkage between the upper and lower, interactive effective communication channels open network system. Fourth, deepen the reform of public service technical service institutions, from the adjustment of the role of various levels of institutions and set the way to achieve the provincial, municipal and county levels of different levels of service functions in the dislocation of development.

Leading enterprises are both the main body of poverty alleviation industry, but also become the main body of science and technology service poverty alleviation, in promoting the development of agricultural economy and promote the spread of agricultural science and technology achievements have unparalleled advantages. Leading enterprises need to protect the profitability of enterprises on the basis of as much as possible to bear some social responsibility to attract more enterprises to participate in poverty alleviation. The government should provide more support for the leading enterprises to carry out science and technology services, one is to innovate the interests of enterprises and farmers to connect the mechanism, the second is for enterprises and research institutions to create conditions for docking, the third is to give full play to the main role of enterprise allocation of resources, and continuously enhance the enterprise The ability to innovate and the core competitiveness.

Innovation of agricultural science and technology services to participate in the main mechanism, through institutional innovation, increase support for all types of subjects involved in poverty-oriented areas to create the conditions for services, and the formation of symbiotic development, both competition and cooperation.

To encourage institutions of higher learning, scientific research institutes to establish agricultural 
technology promotion professor system, to create a pilot demonstration base, to promote scientific research, teaching, promotion of organic integration. The second is to support the institutions of higher learning, scientific research institutes to play the advantages of science and technology, talent and other aspects, focusing on the characteristics of poverty-stricken areas of industry, improve the star world, agricultural science and technology park, agricultural science and technology experts compound, science and technology correspondent workstation and other technology service model. The third is to explore the establishment of an effective mechanism for the active participation of farmers in poverty-stricken areas, and through the partnership with farmers to improve the efficiency of agricultural science and technology through heuristic, interactive and participatory services. Fourth, to strengthen service awareness and service functions, to encourage innovation in service models, to encourage grass-roots exploration and practice, continue to create more realistic, adapt to the market economy of the new model, a variety of successful innovation service

\section{Acknowledgements}

This article is the result of the study of Ya'an anti-poverty in Ya'an City, Sichuan Province in the year of 2016. At the same time, it is supported by Sichuan Agricultural University Scientific Research Interest Group Project " Sichuan Science and Technology Financial Development Mode under the background Whole Creation.

\section{Author Introduction}

ManLu Yang (1998- ), Sichuan Cheng Du, the undergraduate majored in Finance of Economics College in Sichuan Agricultural University.

Yu He * (1984- ), the corresponding author, master of laws, the lecturer of Marxism College in Sichuan Agricultural University, the research direction is the Sinicization of Marxism.

\section{References}

[1] General Secretary Xi Jinping in Sichuan delegation important speech spirit, 2017, 3.13

[2] "Sichuan Province science and technology poverty alleviation special action implementation plan" notice (Chuanke agriculture [2015] 14)

[3] Modern agricultural science and technology service industry development status and countermeasures research report [Z]. Sichuan Provincial Science and Technology Research Report, 2016

[4] Tian Yunhui, Zhao Min, Wang Hai. Incentive scientific and technological personnel innovation and entrepreneurship pilot policy research [Z]. Sichuan Provincial Science and Technology Research Report, 2016

[5] Qiushi. Building a well-off society in full swing is a key step in realizing the Chinese dream On learning and implementing the general layout of General Secretary Xi Jinping on "four comprehensive" strategic layout [J]. Seeking, 2015 (9) 